\title{
Hydrolytic Degradation Study of Lansoprazole, Identification, Isolation and Characterisation of Base Degradation Product
}

\author{
Satyanarayana Battu, Vasudev Pottabathini \\ Department of Chemistry, University College of Science, Osmania University, Hyderabad, India \\ Email: satyambchem@yahoo.co.in, vasudev netha@yahoo.co.in
}

Received 21 December 2014; accepted 16 January 2015; published 20 January 2015

Copyright (C) 2015 by authors and Scientific Research Publishing Inc.

This work is licensed under the Creative Commons Attribution International License (CC BY). http://creativecommons.org/licenses/by/4.0/

(c) (i) Open Access

\begin{abstract}
Lansoprazole degradation is accelerated in both acidic and basic medium in water. The present investigation deals with the hydrolytic degradation of Lansoprazole. Acidic medium degradation show all known impurities and degradation products whereas basic degradation studies show new impurity which has higher molecular weight than Lansoprazole. New impurity was identified, isolated using mass based auto purification system and characterised by ${ }^{1} \mathrm{H}$ NMR, ${ }^{13} \mathrm{C}$ NMR, HMBC, HSQC, NOE, COSY and HRMS experiments. Isolated impurity was showing molecular weight of 467.10, molecular formula of $\mathrm{C}_{23} \mathrm{H}_{16} \mathrm{~F}_{3} \mathrm{~N}_{5} \mathrm{OS}$ and its name is 7-(3-Methyl-4-(2,2,2-trifluoroethoxy) pyridin-2-yl)-7H-benzo[4,5]imidazo[2,1-b]benzo[4,5]imidazo[2,1-d][1,3,5]thiadiazine.
\end{abstract}

\section{Keywords}

Lansoprazole, Hydrolytic Degradation, Isolation, Characterization, Preparative HPLC, ${ }^{1} \mathrm{H}$ NMR, ${ }^{13} \mathrm{C}$ NMR and 2 D NMR

\section{Introduction}

Lansoprazole, 2-(((3-methyl-4-(2,2,2-trifluoroethoxy)pyridin-2-yl)methyl)sulfinyl)-1H-benzo[d]imidazole is a substituted benzimidazole and is an anti-secretory and anti-ulcerativities. It is effective in treating various peptic diseases, especially those resistant to treatment with histamine $\mathrm{H}_{2}$ receptor antagonists. Therefore it is successfully used for the treatment of duodenal ulcer, gastric ulcer, reflux oesophagits and Zollinger Ellison syndrome [1]-[6]. 
In general, active pharmaceutical ingredients (APIs) are formulated with excipients as tablets, syrup and capsules. Since the active ingredient interacts with the excipients and the formulated product is stored at different conditions, the study of API stability is critical in the drug development process. Many factors can affect the stability of a pharmaceutical product, some of them include the stability of the active ingredient, the manufacturing process, and the environmental conditions (such as oxidation, reduction, hydrolysis, and racemization that might occur [7] [8]. The study of stability under stressed conditions is important since it can cause many degradation reactions.

Prevacid I.V. for injection contains $30 \mathrm{mg}$ of the active ingredient of Lansoprazole, $60 \mathrm{mg}$ mannitol, $10 \mathrm{mg}$ meglumine and $3.45 \mathrm{mg}$ sodium hydroxide and is supplied as a sterile, lyophilized powder for I.V. (intravenous) use. Drug is a combination of sodium hydroxide and Lansoprazole, so it is important to study the degradation in basic medium and characterisation of degradation products.

The different analytical techniques were reported so far for the determination of this drug along with corresponding impurities by UV-Visible spectrometry [9]-[12]. Several HPLC assay and LC-MS/MS method for determination of impurities and degradation products of Lansoprazole have been published [13]-[22]. Some research work has been published on characterisation of process related impurities of Lansoprazole [23] [24]. Literature survey indicates that no work is done on the identification, isolation and characterisation of major unknown degradation product formed in the base degradation study. All chemical structures of Lansoprazole and its impurities were shown in Figure 1.

\section{Experimental}

\subsection{Materials}

The investigated sample of Lansoprazole was procured from NOSCH Labs Private Limited, India. Solvents and buffers used for analysis were HPLC grade Acetonitrile and Methanol (Rankem), Ammonium acetate (Fisher Scientific-Qualigens), Ammonium bicarbonate (Sigma Aldrich), Formic acid (Alfa Aesar), Trifluroacetic acid (Alfa Aesar) and Water used was Milli-Q grade.

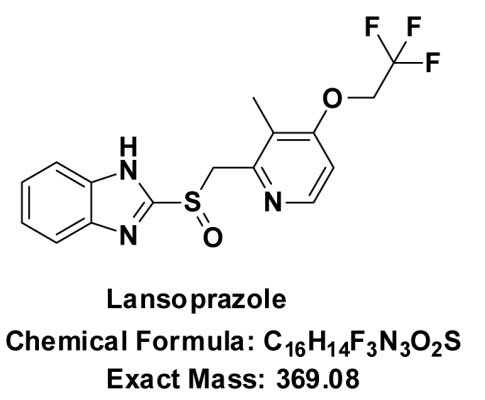

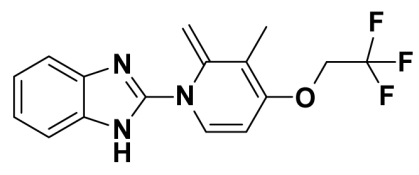

Des Sulphur Impurity Chemical Formula: $\mathrm{C}_{16} \mathrm{H}_{14} \mathrm{~F}_{3} \mathrm{~N}_{3} \mathrm{O}$ Exact Mass: 321.11<smiles>Cc1c(OCC(F)(F)F)ccnc1CSc1nc2ccccc2[nH]1</smiles>

USP Sulphide Impurity Chemical Formula: $\mathrm{C}_{16} \mathrm{H}_{14} \mathrm{~F}_{3} \mathrm{~N}_{3} \mathrm{OS}$ Exact Mass: 353.08<smiles>Cc1cccnc1CS(=O)c1nc2ccccc2[nH]1</smiles>

Reported Impurity Chemical Formula: $\mathrm{C}_{14} \mathrm{H}_{13} \mathrm{~N}_{3}$ OS

Exact Mass: 271.08<smiles>Cc1c(OCC(F)(F)F)ccnc1C1Sc2nc3ccccc3n2-c2nc3ccccc3n21</smiles>

Newly formed Base degradation Product Chemical Formula: $\mathrm{C}_{23} \mathrm{H}_{16} \mathrm{~F}_{3} \mathrm{~N}_{5} \mathrm{OS}$

Exact Mass: 467.10 


\subsection{Equipment}

\subsubsection{Mass Mediated High Performance Liquid Chromatography}

A mass mediated preparative HPLC equipped with waters pump module 2545, UV detector module 2996, mass detector module 3100, sample manager module 2767 and Masslynx data handling system was used. This system was equipped with both analytical port and preparative port. Mass capillary voltage was maintained $3 \mathrm{KV}$, Source temperature $150^{\circ} \mathrm{C}$ and desolvation temperature $350^{\circ} \mathrm{C}$ for the proper ionisation. $0.1 \%$ formic acid is used in water: Methanol (90:10) as a makeup solvent to the mass detector through splitter.

Mass Mediated Analytical HPLC Parameters:

Column: X-Select CSH C18 $(150 \times 4.6,5 \mu)$;

Mobile phase: $10 \mathrm{mM}$ Ammonium bicarbonate (A): Acetonitrile (B);

T/\% of B: 0.01/10, 2/10, 11/90, 11.5/100, 13/100, 13.5/10, 15/10;

Diluent: Mobile phase;

UV detection: $285 \mathrm{~nm}$.

\subsubsection{HRMS (High Resolution Mass Spectrometry)}

Sample was analysed on the waters micro mass Q-TOF equipped with ESI ion source. Sample was analysed in positive mode. Leucine enkephalin $(\mathrm{m} / \mathrm{z}$ : $555.62268 \mathrm{Da})$ was used as internal standard to calibrate the mass range and mass accuracy. Data was acquired in positive mode using Masslynx software.

\subsubsection{Nuclear Magnetic Resonance Spectroscopy $\left({ }^{1} \mathrm{H}\right.$ \& $\left.{ }^{13} \mathrm{C}-\mathrm{NMR}, \mathrm{COSY}, \mathrm{NOE}, \mathrm{HMBC}, \mathrm{HSQC}\right)$}

The ${ }^{1} \mathrm{H}$ and ${ }^{13} \mathrm{C}$ NMR spectra of base degradation impurity were recorded in DMSO- $\mathrm{d}_{6}$ at $400 \mathrm{MHz}$, Bruker 400 MHz advance NMR spectrometer. The ${ }^{1} \mathrm{H}$ and ${ }^{13} \mathrm{C}$ chemical shift are reported on $\delta$ scale in ppm, relative to TMS $(\delta 0.00 \mathrm{ppm})$ and DMSO- $\mathrm{d}_{6}(\delta 39.50 \mathrm{ppm})$ as internal standards respectively.

\section{Hydrolytic Stress Methods}

\subsection{Acid Degradation Procedure}

Acid degradation studies were carried out as per the guidelines of ICH. $200 \mathrm{mg}$ of standard drug was refluxed with $0.1 \mathrm{~N} \mathrm{HCl}$ solution at $60^{\circ} \mathrm{C}$ for $8 \mathrm{~h}$ to study acidic degradation. Normality of acidic solution increased gradually from $0.1 \mathrm{~N}$ to $2 \mathrm{~N}$ to achieve sufficient degradation. For analytical study, the resultant acid degradation sample was dissolved in methanol and diluted with mobile phase and $10 \mu \mathrm{l}$ injected into the system and the chromatograms were recorded to assess the stability of the sample.

\subsection{Base Degradation Procedure}

Base degradation studies were carried out as per the guidelines of ICH. $200 \mathrm{mg}$ of standard drug was refluxed with $0.1 \mathrm{~N} \mathrm{NaOH}$ solution at $60^{\circ} \mathrm{C}$ for $8 \mathrm{~h}$ to study basic degradation. Normality of base solution increased gradually from $0.1 \mathrm{~N}$ to $2 \mathrm{~N}$ to achieve sufficient degradation. For analytical study, the resultant base degradation sample was dissolved in methanol and diluted with mobile phase and $10 \mu \mathrm{l}$ injected into the system and the chromatograms were recorded to assess the stability of the sample.

\section{Results and Discussion}

\subsection{Identification of New Base Degradation Product}

After acid and base degradation the crude sample was injected into the analytical column for the separation of degradation products from the drug peak. To obtain the baseline separation different mobile phases have been used like ammonium acetate, trifluro acetic acid, formic acid, ammonium bicarbonate. Various columns were screened to check the separation and symmetrical peak shape like YMC ODS, YMC Triart, Sunfire, X-terra, X-bride, Agilent zorbax CN, X-Select. Finally desired separation was achieved using the $10 \mathrm{mM}$ ammonium bicarbonate and acetonitrile as a mobile phase and X-Select column $(150 \times 4.6 \mathrm{~mm}, 5 \mu)$. In the developed method observed peaks, retention times, molecular weights and area percentages were shown in below tables (Table 1 and Table 2).

From Table 1 and Table 2, it was clearly observed that in acid degradation study observed all peaks are re- 
Table 1. Degradation products formed in acid forced degradation.

\begin{tabular}{cccccc}
\hline S. No & Peak label & Retention time & Area\% & Observed mass & About the peak \\
\hline 1 & Peak-1 & 8.0 & 10.59 & $322.02(\mathrm{M}+\mathrm{H})$ & Des sulphur impurity \\
2 & Peak-2 & 9.28 & 55.0 & $370.05(\mathrm{M}+\mathrm{H})$ & Lansoprazole \\
3 & Peak-3 & 10.47 & 24.48 & $354.03(\mathrm{M}+\mathrm{H})$ & Sulphide impurity \\
\hline
\end{tabular}

Acid forced degradation products of Lansoprazole.

Table 2. Degradation products formed in base forced degradation.

\begin{tabular}{cccccc}
\hline S. No & Peak label & Retention time & Area $\%$ & Observed mass & About the peak \\
\hline 1 & Peak-1 & 6.93 & 7.37 & $271.98(\mathrm{M}+\mathrm{H})$ & Reported impurity \\
2 & Peak-2 & 9.25 & 37.35 & $370.05(\mathrm{M}+\mathrm{H})$ & Lansoprazole \\
3 & Peak-3 & 10.38 & 8.8 & $354.03(\mathrm{M}+\mathrm{H})$ & Sulphide impurity \\
4 & Peak-4 & 11.27 & 9.9 & Mixture of masses $407.13(\mathrm{M}+\mathrm{H})$, & Unresolved unknown impurities \\
5 & Peak-5 & 12.63 & 16.86 & $462.10(\mathrm{M}+\mathrm{H})$ & Well resolved unknown impurity \\
\hline
\end{tabular}

Base forced degradation products of Lansoprazole.

ported in literature. In base degradation study well resolved unknown major peak of $m / z 468.11(\mathrm{M}+\mathrm{H})$ was not reported in literature. So we intended to isolate $\mathrm{m} / \mathrm{z} 468.11$ by using mass mediated auto purification system. Standard chromatogram of Lansoprazole, acid degradation, base degradation chromatograms and mass spectrums were shown in Figures 2-6.

\subsection{Isolation of Base Degradation Product}

Base degradation study clearly indicates that the peak observed at 12.63 min retention time and having mass $\mathrm{m} / \mathrm{z}$ $468.11(\mathrm{M}+\mathrm{H})$ was new entity in base degradation and remaining peaks were matching with the already reported impurities. To separate this novel impurity formed in base degradation condition, we scaled up the analytical method to preparative scale. Using the same mobile phase and column having dimensions $(150 \times 19 \mathrm{~mm}$, $5 \mu$ ) and a flow rate of $19 \mathrm{ml} \cdot \mathrm{min}^{-1}$ degradation product has been isolated. In mass based preparative system splitter has been used after the column through which flow has been splitted in the ratio of 1000:1. The one part of the flow is passed through mass detector by diluting with make pump using $1 \mathrm{ml} \cdot \mathrm{min}^{-1}$ flow rate. For the proper ionisation of the desired impurity $0.1 \%$ formic acid has been used as it is more volatile and enhances the ionisation. The delay time of the fraction collector has been investigated by using dye at same flow rate and the same parameters have been given as a input to get the good recovery. The crude sample was neutralised with $\mathrm{HCl}$ solution, diluted with mobile phase and injected into the preparative column in three consecutive injections. The fractions have been collected on the basis of mass threshold parameters of total ion chromatogram. After completion of purification collected all fractions of mass $468.11(\mathrm{M}+\mathrm{H})$ pooled together and lyophilized to get free solid.

\section{Structure Elucidation of Base Degradation Product}

Compound $m / z$ : 468.11 obtained from lyophilization characterized by using HRMS, NMR $\left({ }^{1} \mathrm{H}-\mathrm{NMR},{ }^{13} \mathrm{C}\right.$ NMR, HMBC, HSQC, NOE and COSY).

\subsection{High Resolution Mass Spectrometry}

From the mass spectrum it was showing:

1) Monoisotopic mass with even electron ions $(\mathrm{m} / \mathrm{z}$ : $468.0966(\mathrm{M}+\mathrm{H})$ );

2) Elements observed: C: 0-23 H: 0-17 N: 0-5 O: 0-1 S: 0-1;

3) Molecular formula: C23 H17 N5O S (M + H).

From information provided by HRMS report it is matching with expected structure of base degradation product. HRMS report of base degradation product was shown in Figure 7. 


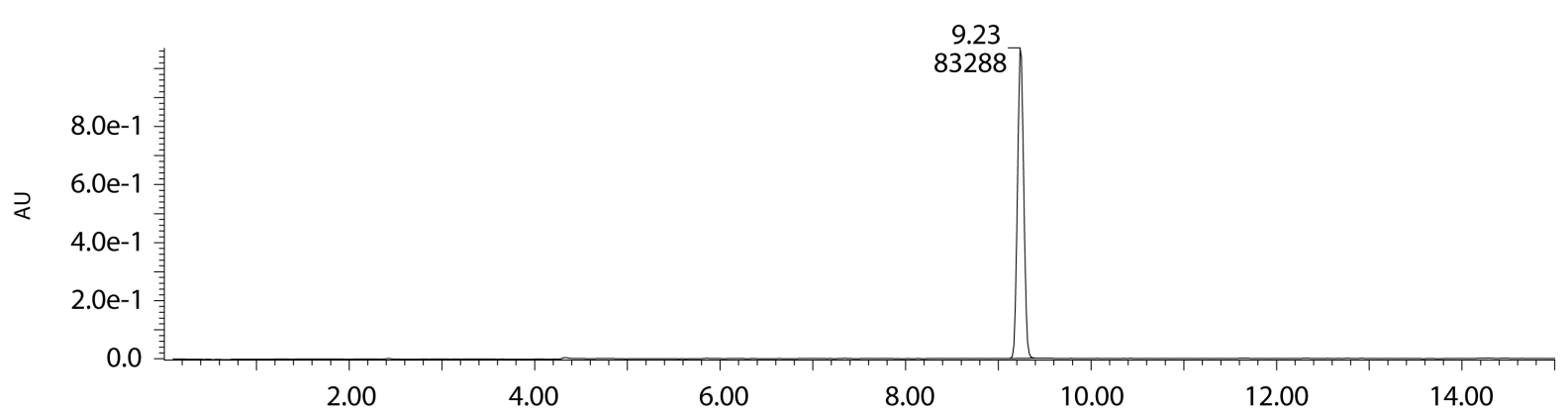

Figure 2. Standard chromatogram of Lansoprazole.

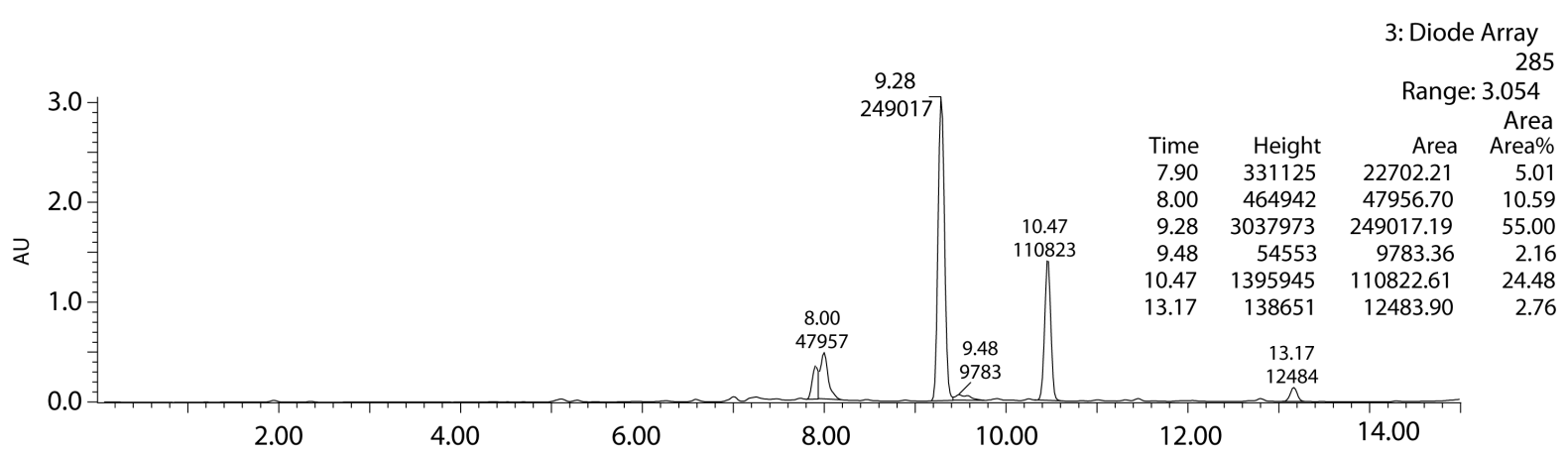

Figure 3. Acid degradation chromatogram of Lansoprazole.
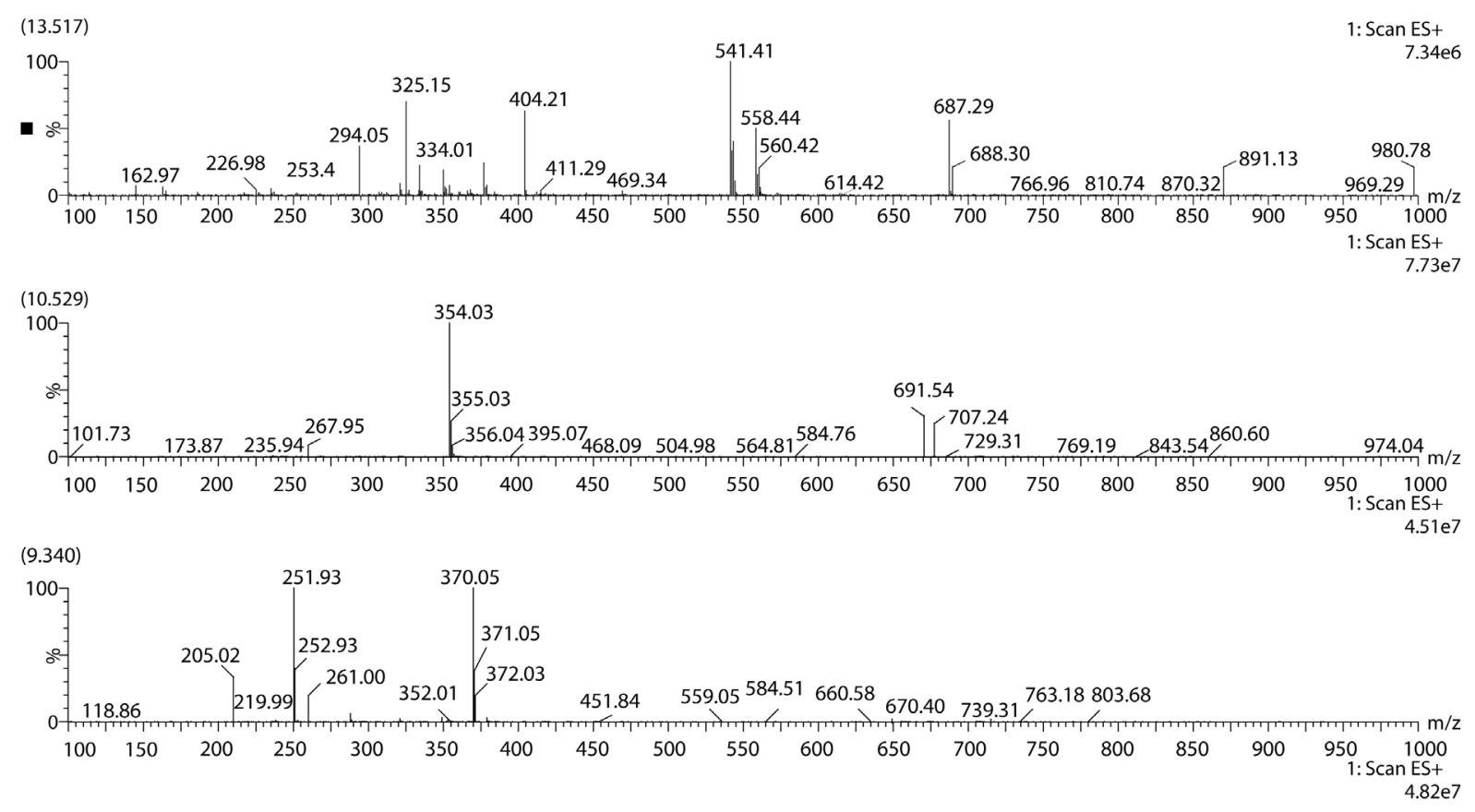

(8.047)

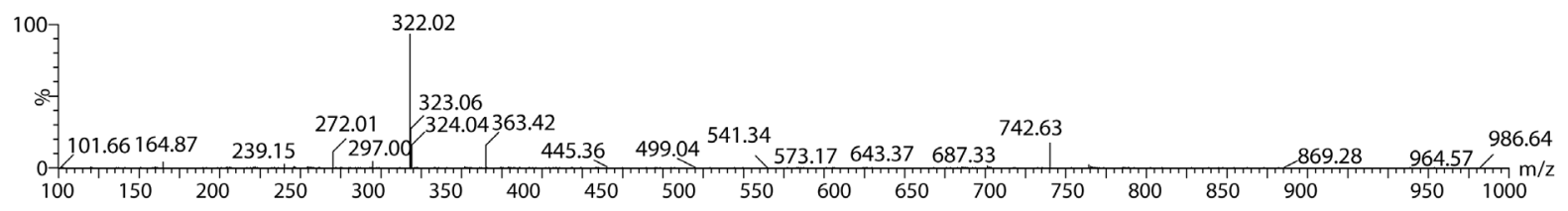

Figure 4. Mass spectrum of acid degradation chromatogram. 


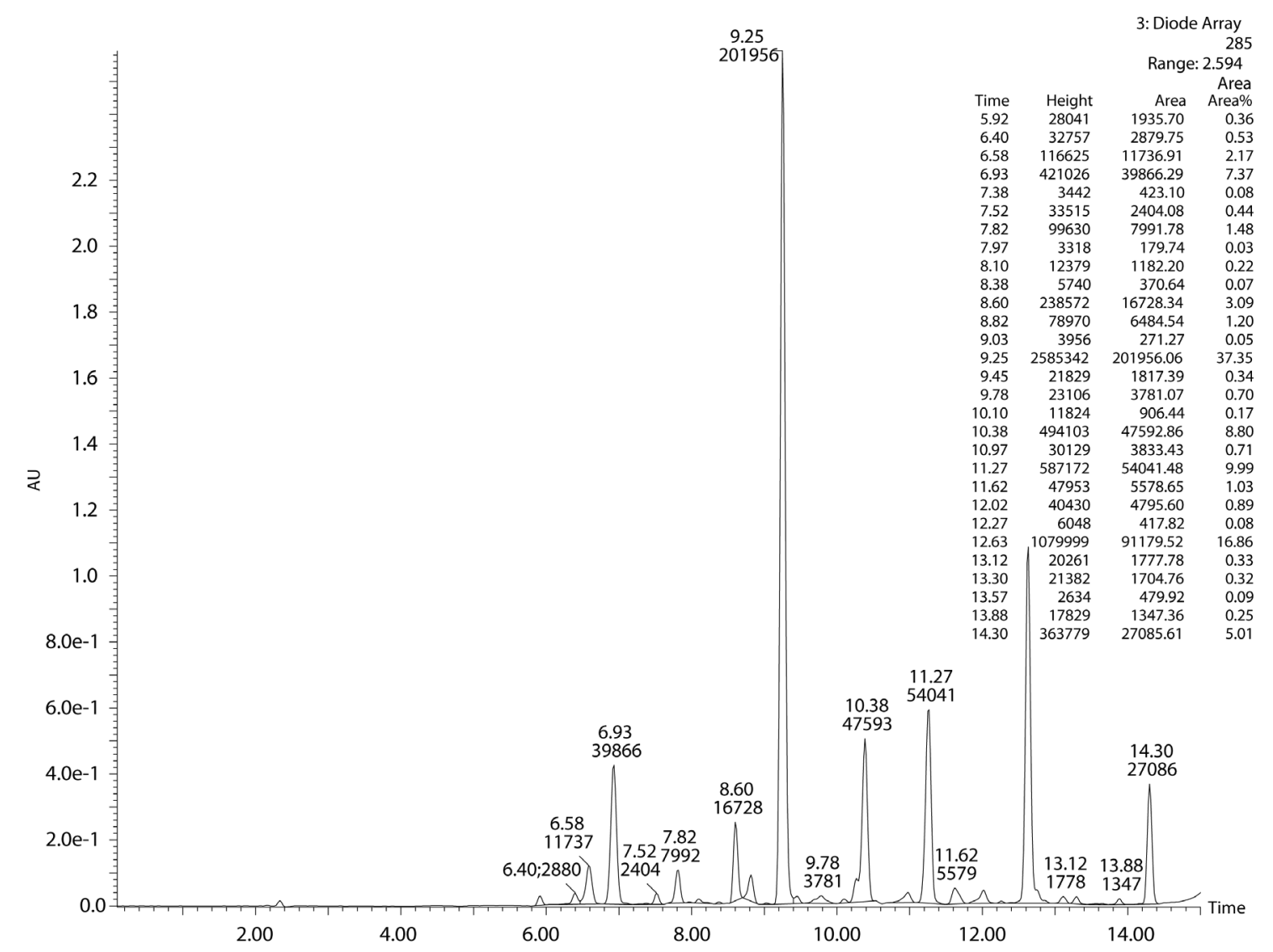

Figure 5. Base degradation chromatogram of Lansoprazole.
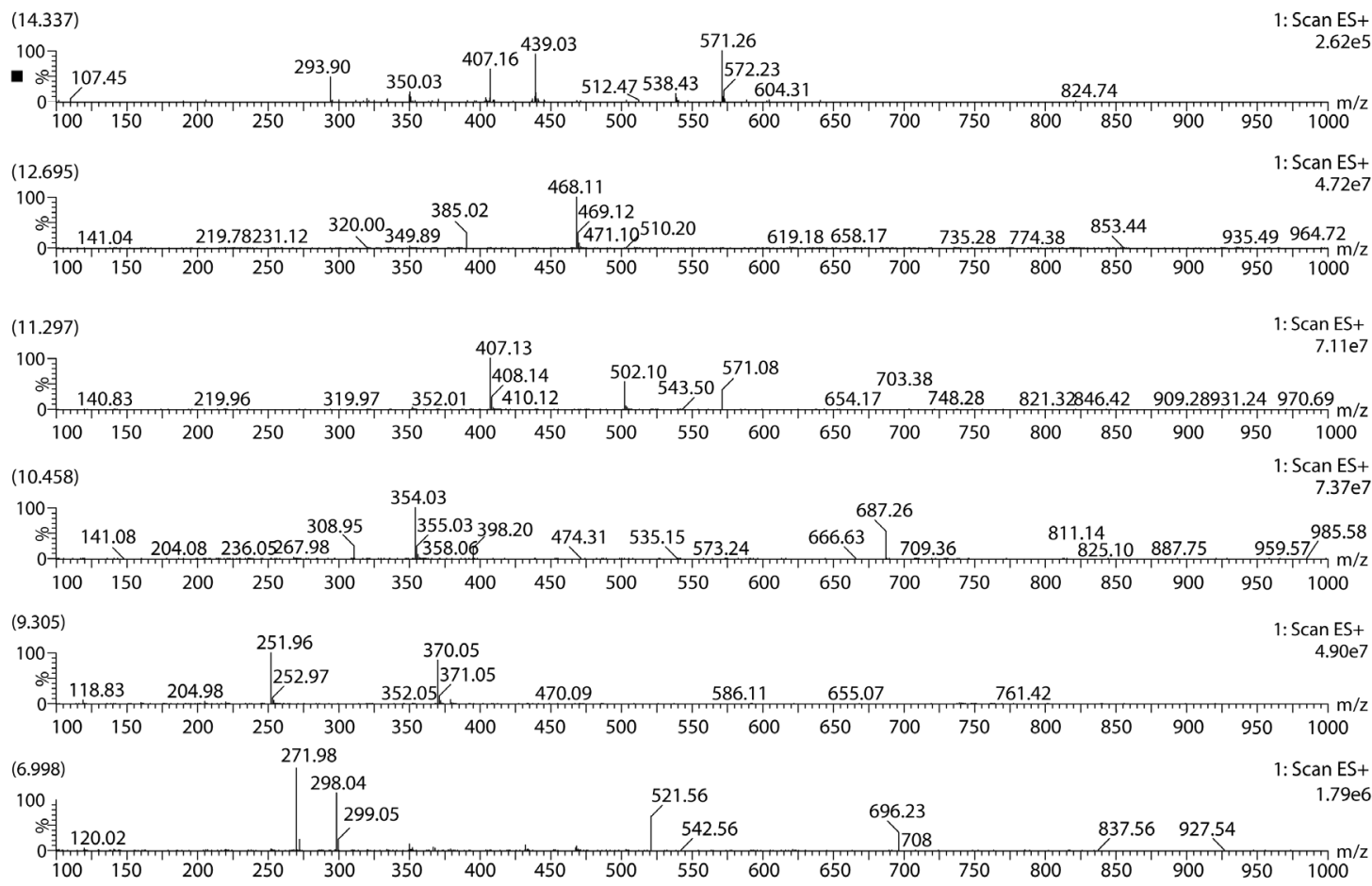

Figure 6. Mass spectrum of base degradation chromatogram. 
Single Mass Analys is

Tolerance $=2500.0$ PPM / DBE $: \min =-1.5, \max =50.0$

Selected filters: None

Monois otopic Mass, Even Electron Ions

87 formula(e) evaluated with 1 results within limits (up to 1 closest results for each mass)

Elements Used:

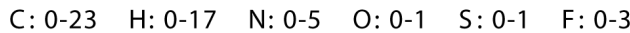

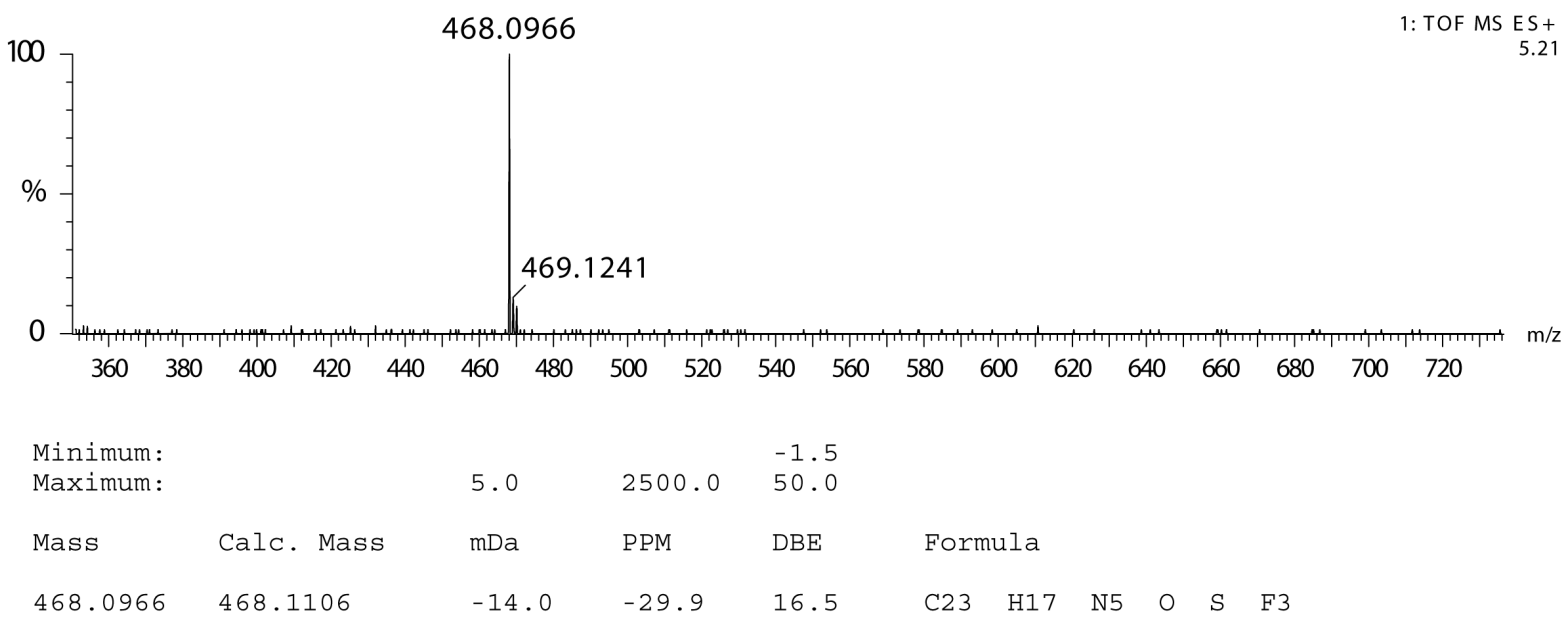

Figure 7. Mass elemental composition report of base degradation product.

\subsection{Nuclear Magnetic Resonance ( $\left.{ }^{1} \mathrm{H} \&{ }^{13} \mathrm{C}-\mathrm{NMR}, \mathrm{HMBC}, \mathrm{HSQC}, \mathrm{COSY}, \mathrm{NOE}\right)$}

The numbering scheme for the NMR assignments and HMBC correlation for critical singlet proton at $7.914 \mathrm{ppm}$ are shown in Figure 8. The ${ }^{1} \mathrm{H}$ NMR, ${ }^{13} \mathrm{C}$ NMR spectral data of degradation product was compared with those of Lansoprazole. In ${ }^{1} \mathrm{H}$ NMR, one set of $-\mathrm{CH}_{2}$ (Methylene) group protons in Lansoprazole are missing in degradation product. As well, in ${ }^{13} \mathrm{C}$ NMR one set of $-\mathrm{CH}_{2}$ (Methylene) group carbon in Lansoprazole missing in degradation product. NMR chemical shifts and 2 D NMR (HSQC, HMBC Correlations) of base degradation product are shown in Table 3. In NOE study, while irradiating proton chemical shift at 7.914 (Label 11) enhancing signals which are spatially closed signals of methyl protons (Label 9) and aromatic proton (Label 28). It clearly indicates presence of benzimidazoles substituted $[1,3,5]$ Thiadiazine. (HMBC, HSQC, NOE and all other NMR data enclosed in supplementary data). ${ }^{1} \mathrm{H}$ NMR spectrum, ${ }^{13} \mathrm{C}$ NMR spectrum, purity chromatogram of degradation product of Lansoprazole and COSY correlation spectrum were shown in Figures 9-12.

From HMBC, Proton of chemical shift at 7.914 singlet (Label 11) giving correlations to the carbons of labels 8, 10, 13, 22 and 29. The above correlation clearly indicates presence of benzimidazoles substituted [1,3,5] Thiadiazine.

From COSY $\left({ }^{1} \mathrm{H}^{-1} \mathrm{H}\right)$ study, assumed structure of base degradation product contains four aromatic doublets and four aromatic triplets in two benzimidazole rings and two doublets in pyridine ring. From cosy spectrum it clearly shows correlations with adjacent protons.

Lable-2 (7.793, d)

Lable-19 (8.533, d)

Lable-16 (7.680, d)

Lable-25 (7.742, d)

Lable-28 $(7.547, \mathrm{~d})$

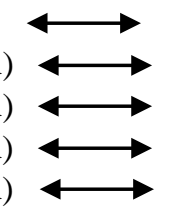

Lable-3 $(6.945, \mathrm{~d})$

Lable-18 $(7.501, \mathrm{t})$

Lable-17 $(7.394, \mathrm{t})$

Lable-26 (7.296, t)

From the above information obtained from the HRMS, ${ }^{1} \mathrm{H}$ NMR, ${ }^{13} \mathrm{C}$ NMR and 2D NMR spectral data it is clearly matching the assumed structure of base degradation product.

\section{Conclusion}

The fast, simple and sensitive method has been optimised for the separation of degradation product of Lanso- 


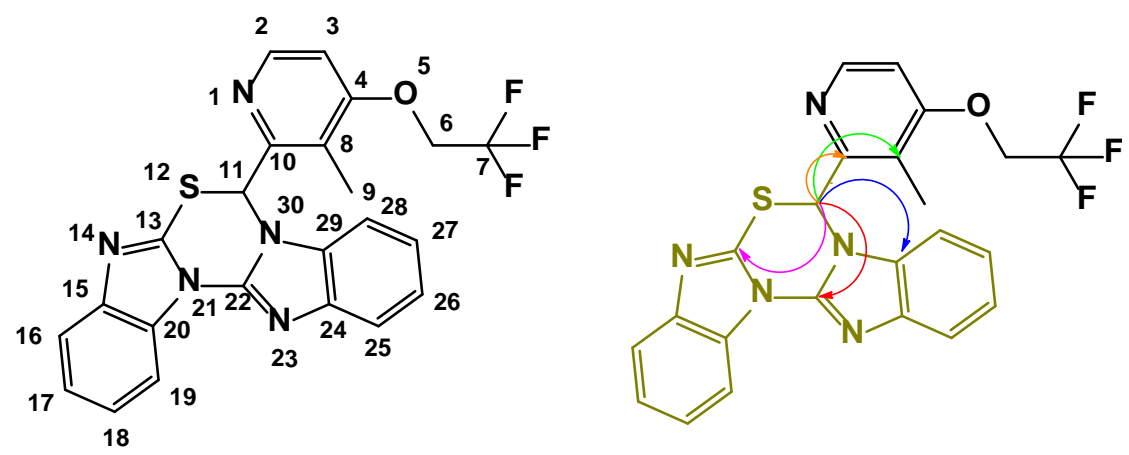

Figure 8. Numbering scheme and HMBC correlation structures of base degradation product.

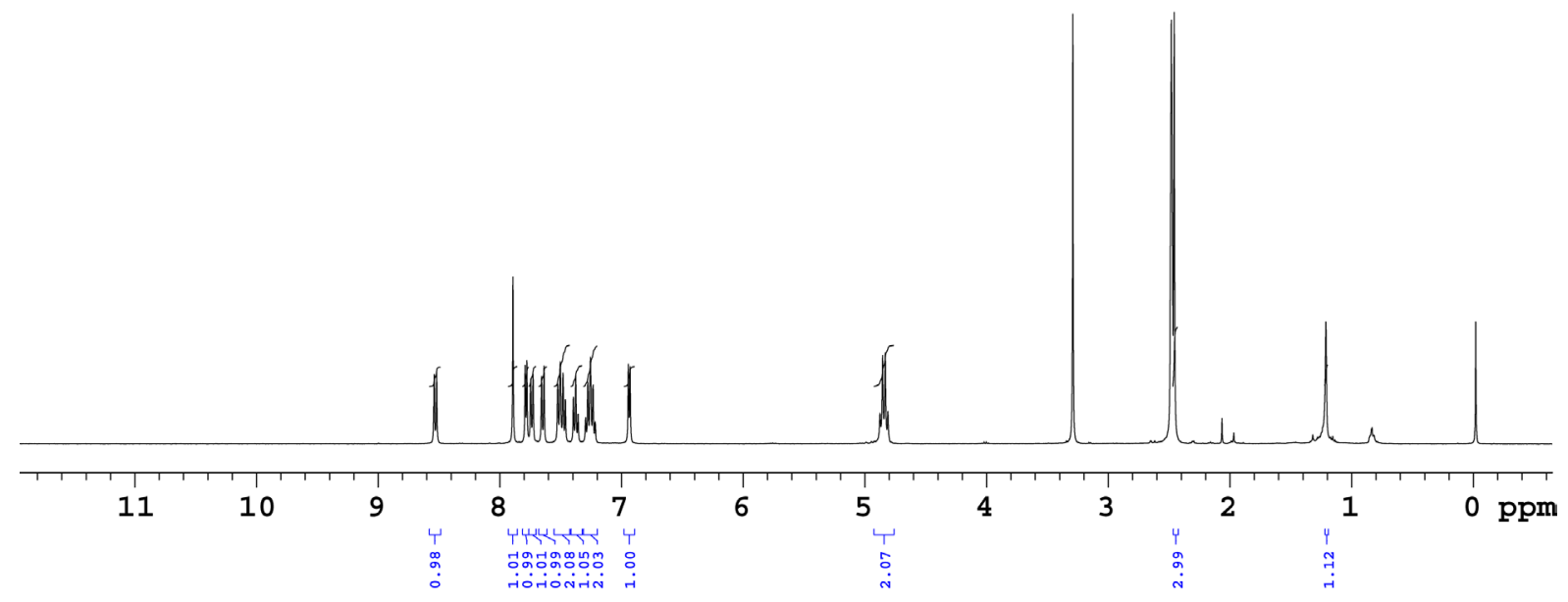

Figure 9. ${ }^{1} \mathrm{H}$ NMR spectrum of degradation product in DMSO.

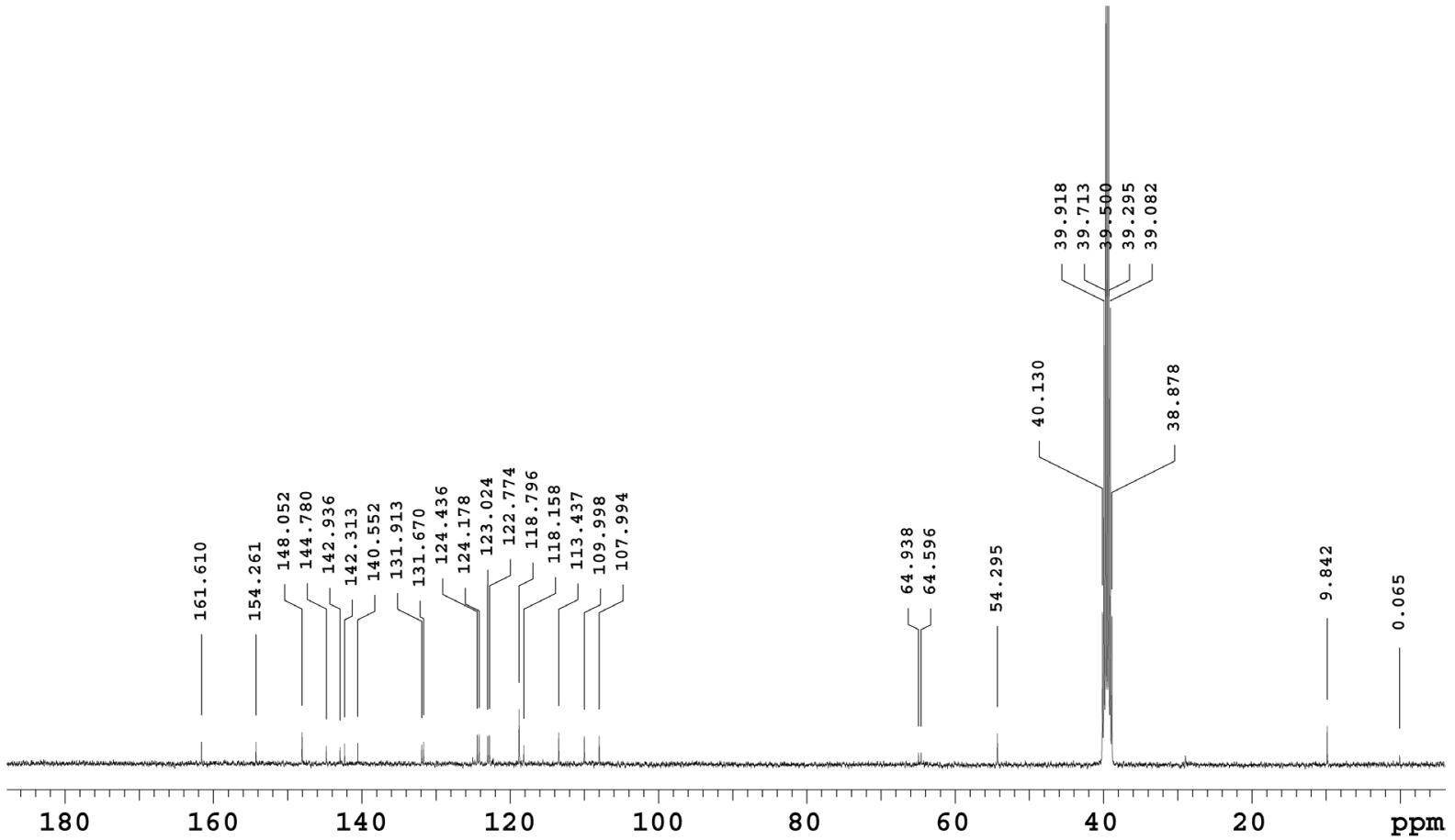

Figure $10 .{ }^{13} \mathrm{C}$ NMR spectrum of base degradation product. 
Table 3. NMR chemical shifts and HMBC, HSQC correlations.

\begin{tabular}{|c|c|c|c|c|c|}
\hline S. No & Label & $\begin{array}{l}{ }^{1} \mathrm{H} \text { Chemical } \\
\text { Shift (in PPM) }\end{array}$ & $\begin{array}{l}{ }^{13} \mathrm{C} \text { Chemical Shift } \\
\text { (in PPM) }\end{array}$ & HSQC & HMBC \\
\hline 1 & 1 & - & - & - & - \\
\hline 2 & 2 & 7.793 (d) & 148.052 & $7.793\left({ }^{1} \mathrm{H}\right), 148.052\left({ }^{13} \mathrm{C}\right)$ & $161.160,107.994$ \\
\hline 3 & 3 & 6.945 (d) & 107.994 & $6.945\left({ }^{1} \mathrm{H}\right), 107.994\left({ }^{13} \mathrm{C}\right)$ & 161.160, 118.158 \\
\hline 4 & 4 & - & 161.160 & $161.160\left({ }^{13} \mathrm{C}\right.$, quartenary) & - \\
\hline 5 & 5 & - & - & - & - \\
\hline 6 & 6 & $4.878(q)$ & 64.596 & $4.478\left({ }^{1} \mathrm{H}\right), 64.596\left({ }^{13} \mathrm{C}\right)$ & $161.160,123.024$ \\
\hline 7 & 7 & - & 123.024 & $123.024\left({ }^{13} \mathrm{C}\right.$, quartenary) & - \\
\hline 8 & 8 & - & 118.158 & $118.158\left({ }^{13} \mathrm{C}\right.$, quartenary) & - \\
\hline 9 & 9 & $2.475(\mathrm{~s})$ & 9.842 & $2.475\left({ }^{1} \mathrm{H}\right), 9.842\left({ }^{13} \mathrm{C}\right)$ & $118.158,161.160,154.261$ \\
\hline 10 & 10 & - & 154.261 & 154.261(quartenary) & - \\
\hline 11 & 11 & $7.914(\mathrm{~s})$ & 54.295 & $7.914\left({ }^{1} \mathrm{H}\right), 54.295\left({ }^{13} \mathrm{C}\right)$ & $\begin{array}{c}\text { 154.261, } 118.158,131.670 \\
142.936,144.780\end{array}$ \\
\hline 12 & 12 & - & - & - & - \\
\hline 13 & 13 & - & 144.780 & 144.780 (quartenary) & - \\
\hline 14 & 14 & - & - & - & - \\
\hline 15 & 15 & - & 142.313 & 142.313 (quartenary) & - \\
\hline 16 & 16 & $7.680(\mathrm{~d})$ & 118.796 & $7.680\left({ }^{1} \mathrm{H}\right), 118.796\left({ }^{13} \mathrm{C}\right)$ & $124.178,131.913$ \\
\hline 17 & 17 & $7.394(t)$ & 124.178 & $7.394\left({ }^{1} \mathrm{H}\right), 124.178\left({ }^{13} \mathrm{C}\right)$ & $113.437,142.313$ \\
\hline 18 & 18 & $7.501(\mathrm{t})$ & 124.178 & $7.501\left({ }^{1} \mathrm{H}\right), 124.178\left({ }^{13} \mathrm{C}\right)$ & 131.913, 118.796 \\
\hline 19 & 19 & 8.533 (d) & 113.437 & $8.533\left({ }^{1} \mathrm{H}\right), 113.437\left({ }^{13} \mathrm{C}\right)$ & $124.178,142.313$ \\
\hline 20 & 20 & - & 131.913 & 131.913 (quartenary) & - \\
\hline 21 & 21 & - & - & - & - \\
\hline 22 & 22 & - & 142.936 & 142.936 (quartenary) & \\
\hline 23 & 23 & - & - & - & - \\
\hline 24 & 24 & - & 140.552 & 140.552 (quartenary) & - \\
\hline 25 & 25 & 7.742 (d) & 118.796 & $7.742\left({ }^{1} \mathrm{H}\right), 118.796\left({ }^{13} \mathrm{C}\right)$ & $122.774,131.670$ \\
\hline 26 & 26 & $7.296(t)$ & 122.774 & $7.296\left({ }^{1} \mathrm{H}\right), 122.774\left({ }^{13} \mathrm{C}\right)$ & 109.998, 140.552 \\
\hline 27 & 27 & $7.254(\mathrm{t})$ & 122.774 & $7.254\left({ }^{1} \mathrm{H}\right), 122.774\left({ }^{13} \mathrm{C}\right)$ & 118.796, 131.670 \\
\hline 28 & 28 & 7.547 (d) & 109.998 & $7.547\left({ }^{1} \mathrm{H}\right), 109.998\left({ }^{13} \mathrm{C}\right)$ & $122.774,140.552$ \\
\hline 29 & 29 & - & 131.670 & 131.670 (qurtenary) & - \\
\hline 30 & 30 & - & - & - & - \\
\hline
\end{tabular}

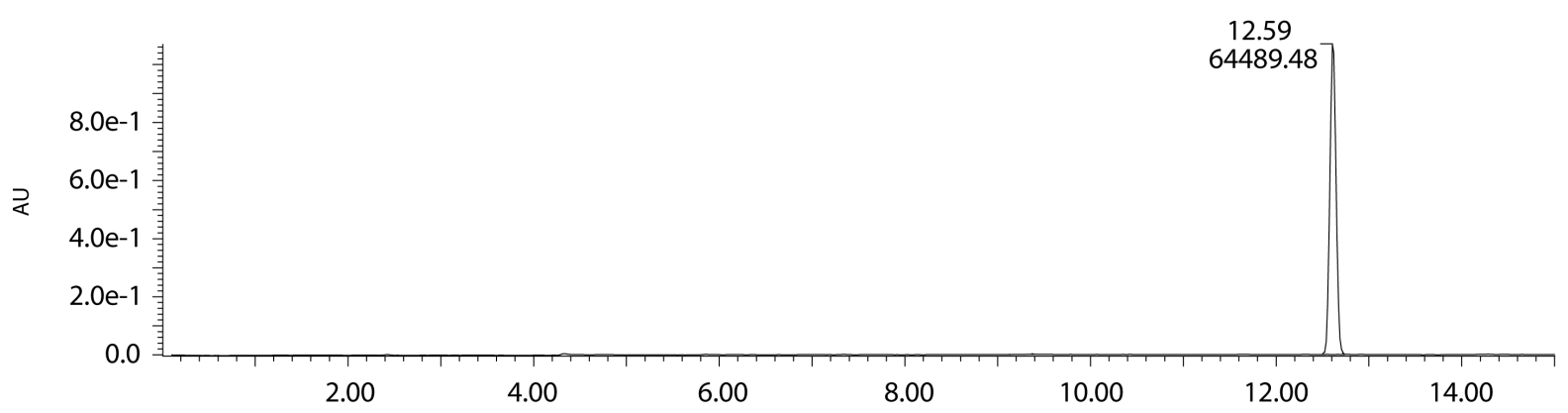

Figure 11. Purity chromatogram of degradation product. 


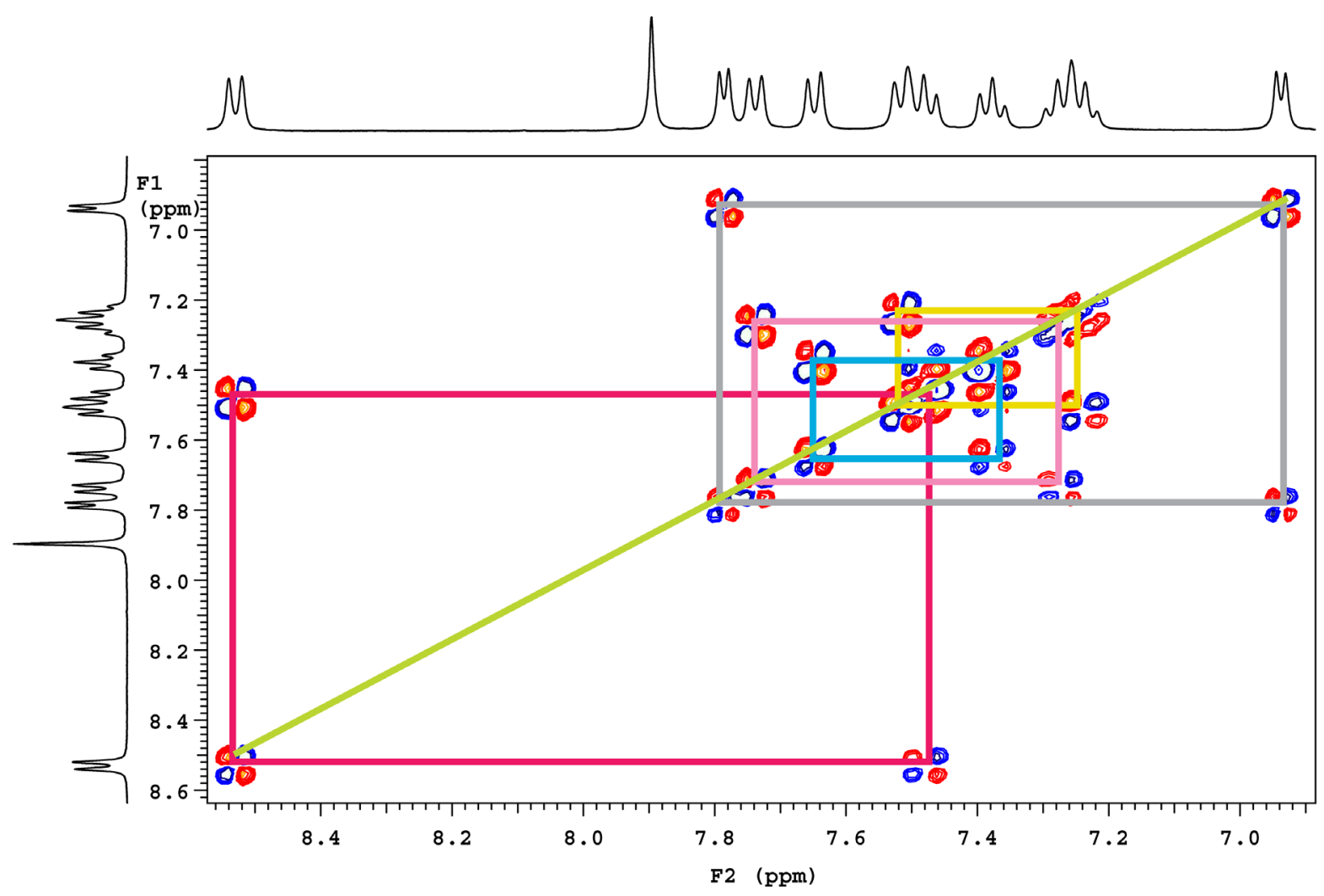

\section{Figure 12. COSY $\left[{ }^{1} \mathrm{H}-{ }^{1} \mathrm{H}\right]$ correlations.}

prazole in hydrolytic stressed condition. The impurity of Lansoprazole formed in base degradation was identified and isolated using a mass mediated preparative HPLC system equipped analytical and preparative ports. Isolated degraded product was characterized by HRMS and NMR $\left({ }^{1} \mathrm{H},{ }^{13} \mathrm{C}\right.$ and HMBC, HSQC, NOE and COSY) techniques. The HRMS and NMR spectral data of isolated product was confirmed to have a mass of 467.10 and with molecular formula of $\mathrm{C}_{23} \mathrm{H}_{16} \mathrm{~F}_{3} \mathrm{~N}_{5} \mathrm{OS}$. It was further confirmed that the isolated base degradation impurity from this method is different from all the reported impurities of Lansoprazole in the literature, having chemical name of 7-(3-Methyl-4-(2,2,2-trifluoroethoxy)pyridin-2-yl)-7H-benzo[4,5]imidazo[2,1-b]benzo[4,5]imidazo [2,1-d]$[1,3,5]$ thiadiazine.

\section{References}

[1] Richter, J.E., Campbell, D.R., Kahrilas, P.J., Huang, B. and Fludas, C. (2000) Lansoprazole Compared with Ranitidine for the Treatment of Nonerosive Gastroesophageal Reflux Disease. Archives of Internal Medicine, 160, 1803-1809. http://dx.doi.org/10.1001/archinte.160.12.1803

[2] Brummer, R.J., Geerling, B.J. and Stockbrugger, R.W. (1997) Initial and Chronic Gastric Acid Inhibition by Lansoprazole and Omeprazole in Relation to Meal Administration. Digestive Disease and Sciences, 42, 132-137.

[3] Tang, G., Serfaty-Lacronsniere, C., Camilo, M.E. and Russell, R.M. (1996) Gastric Acidity Influences the Blood Response to a Beta-Carotene Dose in Humans. American Journal of Clinicle Nutrition, 64, 22-26.

[4] Tolman, K.G., Sanders, S.W., Buchi, K.N., Karol, M.D., Jennings, D.E. and Ringham, G.L. (1997) The Effects of Oral Doses of Lansoprazole and Omeprazole on Gastric pH. Journal of Clinicle Gastroenterology, 24, 65-70. http://dx.doi.org/10.1097/00004836-199703000-00003

[5] Fitton, A. and Wiseman, L. (1996) Pantoprazole: A Review of Its Pharmacological Properties and Therapeutic Use in AcidRelated Disorders. Drugs, 51, 460-482. http://dx.doi.org/10.2165/00003495-199651030-00012

[6] Matheson, A.J. and Jarvis, B. (2001) Lansoprazole: An Update of Its Place in the Management of Acid-Related Disorders. Drugs, 61, 1801-1833. http://dx.doi.org/10.2165/00003495-200161120-00011

[7] Nudelman, N.S. and Estabilidad de (1975) Medicamentos. EI Ateno, Buenos Aires. 
[8] Kommanaboyina, B. and Rhodes, C.T. (1999) Trends in Stability Testing, with Emphasis on Stability during Distribution and Storage. Drug Development and Industrial Pharmacy, 25, 857-868. http://dx.doi.org/10.1081/DDC-100102246

[9] Karljikovic-Rajic, K., Novovic, D., Marinkovic, V. and Agbaba, D. (2003) Journal of Pharmaceutical and Biomedical Analysis, 32, 1019-1027.

[10] Anil Kumar, A., Venkata Ramana, K., Narasimha Raju, C.H. and Sudhakara Rao, G. (2012) A Simple UV Spectrophotometric Method for Determination of Lansoprazole in Bulk and Pharmaceutical Dosage Forms. International Journal of Pharmaceutical, Chemical and Biological Sciences, 2, 524-528.

[11] Alagar raja, M., Yadav, S.K., Rai, A. and Mishra, S. (2011) Analytical Estimation of Lansoprazole and Validation of Simple Spectrophotometric in Bulk and Capsule Formulation. International Journal of Research in Pharmaceutical Sciences, 2, 521-524.

[12] Okram, Z.D., Kanakapura, B., Jagannathamurthy, R.P. and Basavaiah, V.K. (2012) Development of a Simple UV-Spectrophotometric Method for the Determination of Lansoprazole and Study of Its Degradation Profile. Química Nova, 35, 386-391. http://dx.doi.org/10.1590/S0100-40422012000200027

[13] Rao, P.V., Kumar, M.N. and Kumar, M.R. (2013) A Novel, Validated Stability-Indicating UPLC Method for the Estimation of Lansoprazole and Its Impurities in Bulk Drug \& Pharmaceutical Dosage Forms. Scientia Pharmaceutica, 81, 183-193. http://dx.doi.org/10.3797/scipharm.1210-09

[14] Al-Momani, I.F. and Rababah, M.H. (2010) Validation of HPLC and FIA Spectrophotometric Methods for the Determination of Lansoprazole in Pharmaceutical Dosage Forms and Human Plasma. American Journal of Analytical Chemistry, 1, 34-39. http://dx.doi.org/10.4236/ajac.2010.11005

[15] Muthu Kumar, S., Selva Kumar, D., Raj Kumar, T., Udhaya Kumar, E., Suba Geetha, A. and Diwedi, D. (2010) Development and Validation of RP-HPLC Method for the Estimation of Lansoprazole in Tablet Dosage Form. Journal of Chemical and Pharmaceutical Research, 2, 291-295.

[16] Luo, Y.F., Xu, L.S., Xu, M., Feng, J. and Tang, X. (2012) A Validated Specific, Stability Indicating HPLC Method for Determination of Lansoprazole Enteric Coated Capsules and Related Impurities. Asian Journal of Pharmaceutical Sciences, 7, 149-154.

[17] Patel, B., Dedani, Z., Dedani, R., Ramolia, C., Sagar, V. and Mehta, R.S. (2009) Simultaneous Estimation of Lansoprazole and Domperidone in Combined Dosage Form by RP-HPLC. Asian Journal of Research in Chemistry, 2, 210-212.

[18] Brown, S.D., Connor, J.D., Smallwood, N.C. and Lugo, R.A. (2011) Quantification of Lansoprazole in Oral Suspension by Ultra-High-Performance Liquid Chromatography Hybrid Ion-Trap Time-of-Flight Mass Spectrometry. International Journal of Analytical Chemistry, 2011, Article ID: 832414. http://dx.doi.org/10.1155/2011/832414

[19] Katsuki, H., Hamada, A., Nakamura, C., Arimori, K. and Nakano, M. (2011) High-Performance Liquid Chromatographic Assay for the Simultaneous Determination of Lansoprazole Enantiomers and Metabolites in Human Liver Microsomes. Journal of Chromatography B, 757, 127-133. http://dx.doi.org/10.1016/S0378-4347(01)00135-9

[20] Cirilli, R., Ferretti, R., Gallinella, B., Turchetto, L., Zanitti, L. and La Torre, F. (2009) Development and Validation of an Enantioselective and Chemoselective HPLC Method Using a Chiralpak IA Column to Simultaneously Quantify $(R)$ $(+)$ - and (S)-(-)-Lansoprazole Enantiomers and Related Impurities. Journal of Pharmaceutical and Biomedical Analysis, 50, 9-14. http://dx.doi.org/10.1016/j.jpba.2009.03.021

[21] Petkovska, R., Cornett, C. and Dimitrovska, A. (2008) Chemometrical Approach in Lansoprazole and Its Related Compounds Analysis by Rapid Resolution RP-HPLC Method. Journal of Liquid Chromatography \& Related Technologies, 31, 2159-2173. http://dx.doi.org/10.1080/10826070802225478

[22] Srinivas, K.S.V., Mukkanti, K., Buchireddy, R. and Srinivasulu, P. (2010) Detection, Isolation and Characterisation of Principal Synthetic Route Indicative Impurity in Lansoprazole. E-Journal of Chemistry, 7, 844-848.

[23] Reddy, G.M., Mukkanti, K., Laxmi Kumar, T., Moses Babu, J. and Reddy, P.P. (2008) Synthesis and Characterization of Metabolites and Potential Impurities of Lansoprazole, an Antiulcerative Drug. Synthetic Communications, 38, $3477-$ 3489. http://dx.doi.org/10.1080/00397910802162934

[24] Ramulu, K., Rao, B.M. and Someswara Rao, N. (2013) Identification, Isolation and Characterization of Potential Degradation Product in Lansoprazole Drug Substance. Rasayan Journal of Chemistry, 6, 274-283. 
Scientific Research Publishing (SCIRP) is one of the largest Open Access journal publishers. It is currently publishing more than 200 open access, online, peer-reviewed journals covering a wide range of academic disciplines. SCIRP serves the worldwide academic communities and contributes to the progress and application of science with its publication.

Other selected journals from SCIRP are listed as below. Submit your manuscript to us via either submit@scirp.org or Online Submission Portal.
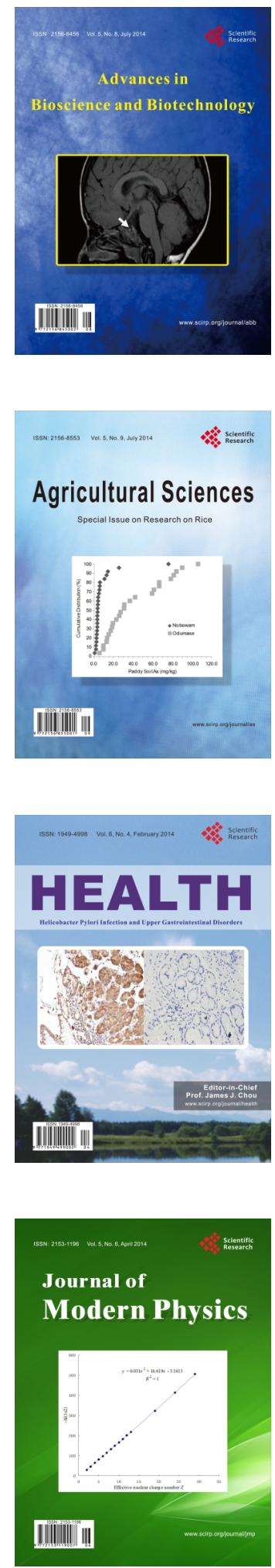
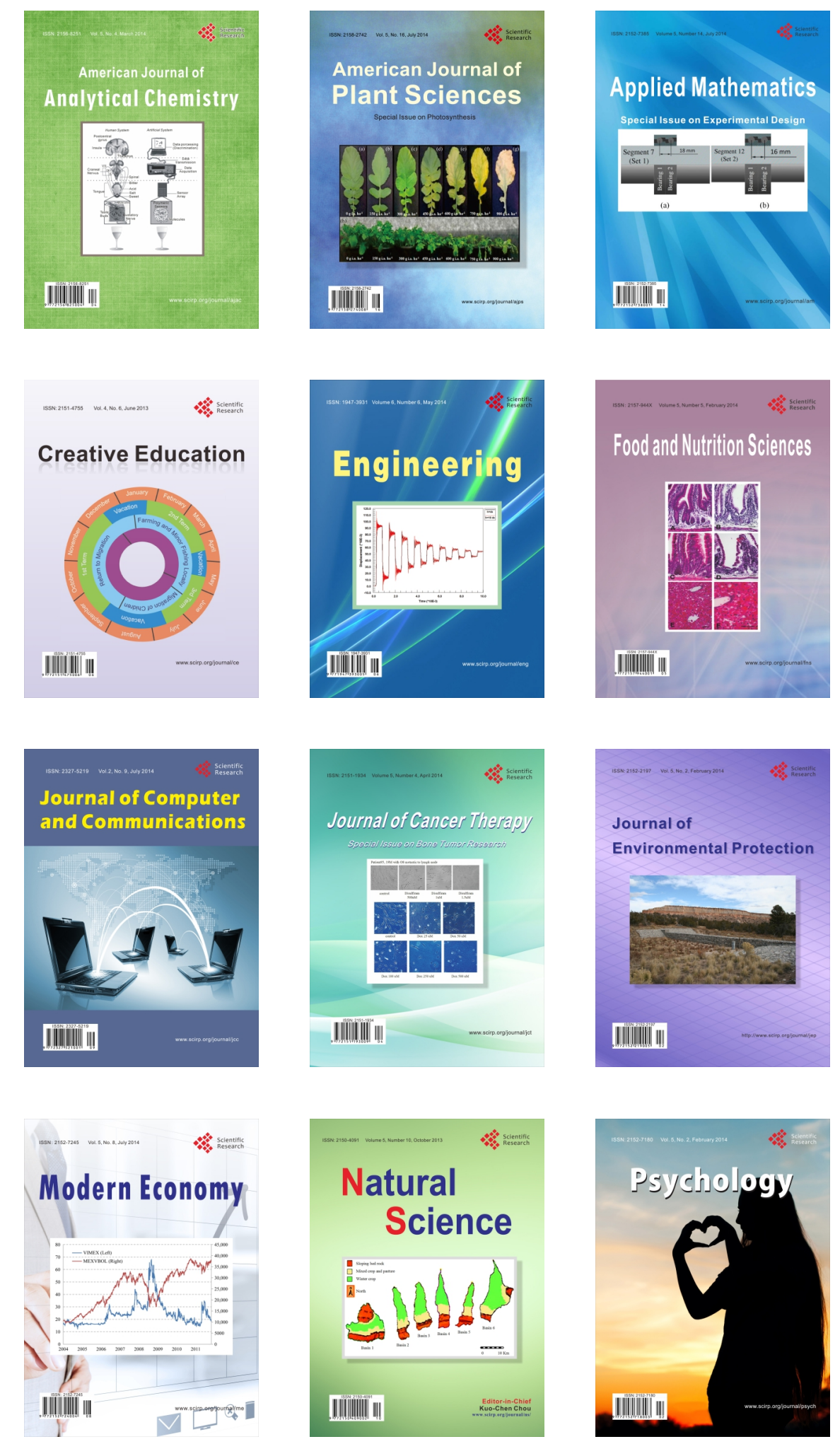